\title{
Comparison of Parent and Child Reports on Child Maltreatment in a Representative Household Sample in Hong Kong
}

\author{
Ko Ling Chan
}

Published online: 28 December 2011

(C) The Author(s) 2011. This article is published with open access at Springerlink.com

\begin{abstract}
This study investigated and compared the rates of child maltreatment as reported by parents and children. Selfreports of 1,093 children aged 12 to 18 , which were matched with both parents' records, were compared and analyzed in the study. The levels of agreement between parent and child reporting of various kinds of parental child maltreatment were low to moderate. Factors affecting the disagreement in reports were also investigated. Social desirability and violence approval were the common predictors of disagreement in father-child and mother-child reports, respectively. The low agreement between parent-child reports found in the present study highlights the need for the inclusion of both parent and child reports on maltreatment in future clinical screening and intervention programs.
\end{abstract}

Keywords Child maltreatment · Parent report · Child report . Reporting · Agreement

Abundant evidence has shown that child maltreatment, including various types of child abuse and neglect, is prevalent worldwide. The prevalence of child maltreatment has been well-documented in Western countries. In the U.S. and European countries, the prevalence rates range from 5\% to $50 \%$ for physical abuse, from $1 \%$ to $36 \%$ for sexual abuse, and around $40 \%$ for child neglect (Hussey et al. 2006; Lampe 2002). When only severe child maltreatment is considered, May-Chahal and Cawson (2005) have found a lifetime prevalence in the U.K. of $7 \%$ for severe physical

\section{K. L. Chan $(\triangle)$}

Department of Social Work and Social Administration,

The University of Hong Kong,

Pokfulam, Hong Kong

e-mail: eklchan@hku.hk assault, $6 \%$ for severe emotional abuse, $11 \%$ for severe sexual abuse, and 5-6\% for absence of care and supervision.

Child maltreatment receives less attention in Eastern countries than in the West (Wong et al. 2009). Despite this lack of research interest, studies have shown that child abuse is not a rare phenomenon in Chinese societies, with the occurrence rates generally resembling those found in Western studies. Existing findings have shown that minor physical abuse is inflicted against $10 \%$ to $23 \%$ of children, and severe to very severe physical abuse occurs among $3 \%$ to $15 \%$ of children in Chinese societies including China, Taiwan, and Hong Kong (Shen 2006; Tang 2006; Wong et al. 2009).

\section{Definitions of Child Maltreatment}

While increasing efforts have been made by researchers to provide a clearer picture of child maltreatment, concerns have arisen regarding the inconsistencies of violence prevalence rates obtained in empirical studies. Such inconsistencies may be due, in part, to the lack of a universally accepted definition of child maltreatment (Cicchetti and Manly 2001). According to the Federal Child Abuse Prevention and Treatment Act (CAPTA; U.S. Department of Health and Human Services 2003, p. 44), the key U.S. federal legislation addressing child maltreatment, child abuse and neglect refers to "any recent act or failure to act on the part of a parent or caretaker, which results in death, serious physical or emotional harm, sexual abuse, or exploitation, or an act of failure to act which presents an imminent risk of serious harm."

In clinical areas, the International Classification of Diseases (ICD; World Health Organization 2004) has often been used as the standard to define child abuse symptoms. However, the definition and conceptualization are less consistent in research fields. In general, child maltreatment includes neglect, physical, 
psychological or emotional abuse, and sexual abuse (Straus et al. 1998). Other researchers have listed additional categories such as moral, legal, and educational maltreatment (Barnett et al. 1993), as well as internet violence. Among these types of maltreatment, the definition of psychological abuse is the most controversial (Kerig and Fedorowicz 1999; McGee and Wolfe 1991), with the placing of exposure to parental violence in the category of psychological aggression still under debate (Hart et al. 1998). Another issue is whether maltreatment should be defined by the behavior of the perpetrator, the experience of the child, or some combination of the two (Barnett et al. 1993). Overall, researchers have arrived at a consensus that a clearer and more universal definition is needed for more accurate investigation of child maltreatment (Kerig and Fedorowicz 1999; Runyan et al. 2005; Shor 1998).

\section{Sources of Reports: Parents Versus Children}

The reliance on only one informant (i.e., either the parent or child) might also affect the reliability of findings from past studies (Fantuzzo and Lindquist 1989). Kerig and Fedorowicz (1999) have noted that most research studies using parents as informants obtained data from one parent only and tended to focus on the mothers' reports. Parent reports of child maltreatment may involve response bias and thus provide significant underestimates (Kaufman et al. 1993; Kolko et al. 1996). Factors affecting the reliability of parent reports may include shame, denial, and fear of future legal consequences (Appel and Holden 1998; Cicchetti and Olsen 1990); memory deficits due to the passage of time (McGee et al. 1995); and limited ability to recall information due to posttraumatic stress disorder (PTSD) symptoms when the parent informant also experiences domestic violence (Briere 1992).

The use of child reports is believed to be more accurate and informative in estimating the prevalence of child maltreatment (McGee et al. 1997; Richters and Martinez 1993; Winegar and Lipschitz 1999). However, such reports are not free from limitations. Maltreated children tend to underreport or minimize the amount of abuse they have experienced (Jouriles et al. 1997; McGee et al. 1995), as they often feel a sense of loyalty to the abusive family or parent (Jaffe et al. 1992), or suffer from PTSD symptoms that hinder their accurate recall of information (Graham-Bermann et al. 2006). The use of selfreport measures for children may also be problematic as they are often developed by adults whose concepts and constructs of child maltreatment may not be the same as children's. Even for the widely used measure, the Parent-child Conflict Tactics Scale (CTSPC; Straus et al. 1998), the authors have admitted that the measure has its own limitations such as covering only the current caregiver and only limited violent acts, which could lead to lower estimates of the child maltreatment rates (Straus 2007).
To avoid any mono-informant bias resulting from the reliance on a single informant, researchers have stressed the importance of employing multiple sources of information to provide details about abusive events (Kaufman et al. 1994). Past studies have compared parent and child self-reports of child maltreatment and found low to moderate correlation or agreement between the reports. In particular, Jouriles and Norwood (1995) found a moderate correlation between mother and child reports of physical assault, while Kolko et al. (1996) found only a low to moderate correspondence.

\section{Correlates of Child Maltreatment and Its Reporting}

The discrepancy in self-reports of parents and children may stem from the difference in reporting styles, which are greatly influenced by the informant's characteristics. As well as the fear of future court actions (Appel and Holden 1998; Cicchetti and Olsen 1990), an informant's level of social desirability may be another major factor affecting disclosure of domestic violence (Arias and Beach 1987; Rosenbaum and Langhinrichsen-Rohling 2006). Informants with a high level of social desirability wish to be viewed positively and are therefore more likely to underreport violent incidents. In fact, Arias and Beach (1987) have discovered a negative association between social desirability and the willingness to report physical violence perpetration.

Apart from social desirability, Straus et al. (1999) have also suggested other possible factors that are related to family violence. Negative attribution, which refers to the negative intentions or blame attributed to the victims of violence, and violence approval, the extent to which violence is acceptable in a variety of interpersonal situations, are examples of these factors. Parents with a high level of negative attribution tend to believe their use of violence is due to the children's fault, while those who approve violence may not regard their acts as problematic. These parents may therefore be less likely to report their violent acts which are socially undesirable and even criminal.

Cultural values may also exert an influence on the perception, tolerance, and reporting of child maltreatment. Asian societies, including Chinese populations, are believed to have cultures and traditions that can be very different to those of Western populations. These specific cultural backgrounds, such as patriarchal authority and the principle of filial piety and unquestioning obedience for children in China, may lead to different patterns of prevalence or reporting of child maltreatment (Chan 2009b). Indeed, past findings have often revealed a higher tolerance for parental physical aggression as disciplinary practices among Chinese populations (Hong and Hong 1991; Wong et al. 2009). In addition, the Chinese concept of face (mien-tzu) may play an important role in the reporting of violence (Chan 2009a). According to Carr (1993, 
p. 90), mien-tzu can be translated as "prestige; dignity; honor; respect; status" that can be gained or lost through interaction with others. Since perpetrating child maltreatment is socially undesirable and may lead one to "lose face" and bring shame on the family (Ho 1990), the abusive parent may refrain from disclosing violent acts. Therefore, a greater need to save face may increase the tendency for parents to underreport, as well as explain the discrepancy between parent and child reports.

As shown by past findings, demographic factors are often associated with child maltreatment. Education level, one indicator of socioeconomic status, was found to be negatively associated with the reported rates of child neglect (Scher et al. 2004); that is, individuals with lower education levels were more likely than their more educated counterparts to report being victimized by child neglect. Furthermore, child age and parental age have also been found to be related to child maltreatment and its reporting. It has been shown that younger aged children, such as infants, were more likely than older children to be victimized by child maltreatment (Chance and Scannapieco 2002). Similarly, young parental age, especially maternal age, is often associated with a higher likelihood to neglect children (Brown et al. 1998; Chaffin et al. 1996).

\section{The Present Study}

Taking into consideration the concerns about the reliability of reports from a single source of information, the present study investigated and compared the prevalence of child maltreatment as reported by parents and children. Using a large and representative parent-child matched sample of Chinese families, the study examined the levels of agreement between the matched parent and child reports of different types of child maltreatment, and investigated whether the demographic characteristics (such as age and education level) and psychological characteristics (such as social desirability and face) of parents would be predictive of discrepancies between reports. In order to facilitate comparison, the widely used Conflict Tactics Scale Parentchild Version (Straus et al. 1998), a structured measure developed for the assessment of child maltreatment, was employed. The use of such a structured measure is believed to be effective in reducing inaccurate responses as well as in providing an opportunity for investigators to explain the questions more thoroughly (Bifulco et al. 1994).

\section{Method}

Sample

The present study employed data from a representative household survey conducted in Hong Kong in 2004 (hereafter "the 2004 study"). In the 2004 study, eligible households were sampled using a stratified sampling procedure. Living quarters were sampled from the Register of Quarters that is maintained by the Census and Statistics Department of the Government of Hong Kong with two stratification factors: (a) housing type (publicly subsidized or private) and (b) geographic region. This was an effort to ensure that respondents were drawn from different socioeconomic levels. Of the 4,356 living quarters sampled, $70 \%$ agreed to participate. Nonparticipation encompassed both refusals to participate $(20 \%)$ and failure to contact potential participants $(10 \%)$.

All Chinese children aged 12 to 17 years, whose parents were married, cohabiting, single, or divorced, were recruited to participate. Children under 12 were not interviewed out of concern that they might not understand some of the questions. Children and their parents gave informed consent prior to the interviews, and all were informed that they could refuse to answer any question at their wish. Interviews were conducted separately on children and their parents from the same family to ensure data confidentiality. Items on sensitive issues were grouped into a separate, self-administered questionnaire which was to be completed and sealed in an envelope by the participants themselves. All interviewers were trained on the ethical issues related to working with participants who reported abuse. Participants were given an information card containing details of social services related to violence prevention and intervention. The study was approved by the ethics committee of the University of Hong Kong.

A parent-child matched subsample of data, with a total of 1,093 children with both parents, was analyzed in the present study. The children sample was $50 \%$ male, with a mean age of $14.49(S D=1.75)$. A complete profile of the matched sample is shown in Table 1.

\section{Measures}

Child Abuse and Neglect The Parent-child Conflict Tactics Scale (CTSPC; Straus et al. 1998) was used to assess the prevalence of lifetime child maltreatment and child maltreatment in the year preceding the study. The 32-item CTSPC included acts and behaviors covering four aspects of child maltreatment: (a) physical assault, (b) psychological aggression, (c) neglect, and (d) nonviolent disciplinary behaviors (nonviolent discipline). In the present study, all CTSPC items were rated on a yes/no scale. There were two versions of the scale, one of which was to be completed by children and the other by parents. The CTSPC was translated into Chinese in the present study using a back-translation procedure (Maxwell 1996) in which the items were translated into Chinese by a bilingual translator, then back-translated into English by another, and finally, original and back-translated versions of English items were compared by a third researcher. This procedure was repeated until agreement between the two English versions reached a satisfactory level. With values of 
Table 1 Demographic characteristics of respondents

\begin{tabular}{llll}
\hline Characteristics & \multicolumn{2}{l}{ Percentage (\%) } & $\chi^{2 / T-t e s t}$ \\
\cline { 2 - 3 } & $\begin{array}{l}\text { Total } \\
(n=1,093)\end{array}$ & $\begin{array}{l}\text { Boys } \\
(n=546)\end{array}$ & $\begin{array}{l}\text { Girls } \\
(n=547)\end{array}$ \\
\hline
\end{tabular}

Child-related

Age (mean, SD)

Education level $^{\mathrm{a}}$

Primary

Lower secondary

Upper secondary

No. of siblings

0

1

2 or more

New arrival from

Mainland China

Disability (physical

or mental)

Father-related

Age

$20-39$
$40-5$

55 or above

Education level $^{\mathrm{a}}$

Lower secondary or

below

Upper secondary

Tertiary or above

New arrival from

Mainland China

Unemployment

Income $^{\mathrm{b}}$ [monthly]

No income

$\$ 4,999$ or below

$\$ 5,000$ or above

Mother-related

Age

$20-39$
$40-54$
55 or above

Education level ${ }^{\mathrm{a}}$

Lower secondary or

below

Upper secondary

Tertiary or above

New arrival from

Mainland China

Unemployment

Income $^{\mathrm{b}}$ [monthly]

No income

$\$ 4,999$ or below

$\$ 5,000$ or above

Family-related

Marital status of parents

Married/ cohabiting

Separated/ divorced

Widowed

$\begin{array}{llll}14.49,1.75 & 14.59,1.75 & 14.38,1.74 & 1.93 \\ & & & 4.22\end{array}$

$\begin{array}{lll}11.3 & 9.5 & 13.2\end{array}$

$\begin{array}{lll}55.4 & 55.5 & 55.4\end{array}$

$33.2 \quad 35.0 \quad 31.4$

47.3

43.6

9.1

6.6

0.4

50.9

40.8

8.2

6.0

0.2

0.52

1.00

4.06

$\begin{array}{lll}9.4 & 8.9 & 9.9\end{array}$

$\begin{array}{lll}79.8 & 82.2 & 77.4\end{array}$

$\begin{array}{lll}10.8 & 8.9 & 12.7\end{array}$

62.3

30.8

6.9

0.9

7.8

10.7

7.9

81.5

23.7

73.0

3.3

67.0

28.0

5.0

7.0

3.2

47.5

15.2

37.3

47.9

15.8

36.6

93.1

5.4

1.5
Table 1 (continued)

\begin{tabular}{|c|c|c|c|c|}
\hline \multirow[t]{2}{*}{ Characteristics } & \multicolumn{3}{|c|}{ Percentage $(\%)$} & \multirow[t]{2}{*}{$\chi^{2} / T$-test } \\
\hline & $\begin{array}{l}\text { Total } \\
(n=1,093)\end{array}$ & $\begin{array}{l}\text { Boys } \\
(n=546)\end{array}$ & $\begin{array}{l}\text { Girls } \\
(n=547)\end{array}$ & \\
\hline $\begin{array}{l}\text { Chronic illness or } \\
\text { disability of parent(s) }\end{array}$ & 16.2 & 16.3 & 16.0 & 0.02 \\
\hline Indebtedness of parent(s) & 8.7 & 9.6 & 7.7 & 0.98 \\
\hline Receiving social security & 7.2 & 5.7 & 8.7 & 2.83 \\
\hline
\end{tabular}

${ }^{\text {a }}$ Primary $=$ grades $1-6$ in the U.S.; Lower secondary=grades 7-9; Upper secondary $=$ grades $10-12$

${ }^{\mathrm{b}}$ In Hong Kong dollars (HKD), where 1HKD 0.13USD

.58 (nonviolent discipline), .61 (neglect), .74 (psychological aggression), and .87 (overall physical assault), the reliability coefficients of the translated subscales were satisfactory to good in the present study.

Personal and Relationship Profile (PRP) The PRP is a selfreporting measure consisting of 21 factors theoretically related to domestic violence (Straus et al. 1999). Three subscales - negative attribution, violence approval, and social desirability - were selected in the present study. Respondents rated their agreement with each item on a 4-point Likert scale ( $1=$ strongly disagree; $4=$ strongly agree), and item ratings in each subscale were summed into a subscale score. The score ranged from 4-16 for negative attribution, from 9-36 for violence approval, and from 13-52 for social desirability; the higher the score, the higher level of the influence of the constructs on participants. All items used in the present study had been translated and back-translated by professionals to obtain a Chinese version. The reliability coefficients of the Chinese version of negative attribution, violence approval, and social desirability were $.92, .83$, and .55 respectively.

Face The Acquisitive Face Orientation Scale (AFOS) was used to measure the concept of face in the Chinese population. The AFOS is a validated 10-item scale rated on a 4-point Likert scale ( $1=$ strongly disagree; $4=$ strongly agree $)$. The 10 statements cover the following areas: (a) demonstrating one's strengths to others; (b) happiness receiving attention or admiration; (c) liking fancy houses, offices, or cars; (d) advertising one's success; (e) being a person who is admired by others; (f) being a celebrity; ( $\mathrm{g}$ ) being supported and respected; (h) honoring family and ancestors; (i) admiring prestigious, powerful, or high status people; and (j) seizing opportunities to be a leader. The total score ranged from 10 to 40 , with a higher score indicating a greater effect of face on the behaviors and cognitions of participants. The internal consistencies were satisfactory to good, with Cronbach's alpha ranging from .70 in a previous study (Wang 2002) to .93 in the present study. 


\section{Questionnaires}

Child's Version The child participants were asked to respond to the child's version of the CTSPC and questions concerning demographic information (age, education level, number of siblings, whether they were new arrivals from Mainland China, and whether they had any physical or mental disability).

Parent's Version Both parents of the child were interviewed separately using the parent's version of the questionnaire, consisting of the parent's form of the CTSPC, the selected subscales of the PRP, as well as items about age, education level, marital status, employment status, income, and whether they were in any debt during the time of interview (indebtedness). The families were also asked whether any parent was receiving social security, was in debt, and had a chronic illness or disability.

\section{Statistical Analyses}

Prevalence of Child Maltreatment The prevalence rates of child-reported and parent-reported child maltreatment were summarized by type under two time frames: over the child's lifetime and during the year preceding the interview.

Parent-Child Agreement in the Reporting of Child Maltreatment The parent-child matched sample allowed the present study to compare the self-reported child maltreatment prevalence between children and their parents and to investigate the agreement in these self-reports. To test the degree of agreement, Cohen's kappa coefficient analysis was employed. Cohen's kappa is a robust measure that evaluates interrater agreement and has a value ranging from 0 to 1 . A greater value indicates a higher level of agreement between raters (or respondents). In general, a kappa value below .20 represents a low level of agreement, a value around .50 implies a moderate agreement, and a value above .80 indicates an excellent agreement (Landis and Koch 1977). Taking into account the possible gender differences in violence reporting, the present study compared the reports between (a) father and son (fatherboy), (b) father and daughter (father-girl), (c) mother and son (mother-boy), and (d) mother and daughter (mother-girl).

Factors Affecting the Disagreement Between Reports Logistic regression analyses were conducted to study the effect of the child's age and education level, the parent's age and education level, face, negative attribution, violence approval, and social desirability on the disagreement between child and parent reports. Odds ratios resulting from the analyses were used as a reference for the investigation of the potential effect of these factors. Two separate series of logistic regression were conducted, with one focusing on the effect of the father's characteristics on the father-child disagreement and the other focusing on the effect of the mother's characteristics on the mother-child disagreement.

In the present study, a $p$-value below 0.05 was considered statistically significant, and all statistical analyses were performed in SPSS version 17.

\section{Results}

Child-Reported Prevalence of Child Maltreatment

The child-reported prevalence of maltreatment by fathers and mothers is shown in Table 2. Overall, the rates of lifetime experience of physical assault, psychological aggression, and neglect by fathers were $37.1 \%, 63.3 \%$, and $29.1 \%$, respectively. The rates of maltreatment by fathers in the preceding year were $16.7 \%$ for physical assault, $45.2 \%$ for psychological aggression, and $21.2 \%$ for neglect. The prevalence of the three types of child maltreatment by mothers followed a similar pattern. The rates of physical assault, psychological aggression, and neglect as reported by children were respectively $35.7 \%$, $61.0 \%$, and $27.2 \%$ over lifetime, and $17.4 \%, 46.7 \%$, and $21.2 \%$ in the preceding year.

When comparing the rates of child maltreatment as reported by boys and girls, no significant gender difference was found, except for the rates of severe and very severe physical assault by mothers in the preceding year. Specifically, girls were more likely than boys to report experiencing severe $\left(11.7 \%\right.$ versus $\left.7.9 \% ; \chi^{2}=4.48, p<.05\right)$ and very severe $(3.7 \%$ versus $\left.1.5 \% ; \chi^{2}=5.23, p<.05\right)$ levels of physical assault. When the rate of experiencing either severe physical assault, very severe physical assault, or a combination of the two was considered, girls again were more likely to report maltreatment by mothers than were boys $\left(12.1 \%\right.$ versus $8.4 \%$; $\chi^{2}=$ $3.90, p<.05)$.

\section{Agreement Between Father and Child Reports}

Table 3 shows the comparison of father and child reports on maltreatment by fathers. In general, significant differences were found between father and child reports of most types of maltreatment. Regardless of the time frame used to assess violence (i.e., lifetime or preceding year), children were more likely to report severe and very severe physical assault, as well as neglect by fathers, whereas fathers tended to report higher rates of nonviolent disciplinary behaviors. In addition, fathers were also more likely to admit minor physical assault and psychological aggression against children in the preceding year.

When the father and child reports were matched, the percentages of father-child disagreement on different types of maltreatment ranged from $3 \%$ to $35.4 \%$. The kappa coefficients 
Table 2 Prevalence of parent's perpetration of violence against children, as reported by boys and girls

\begin{tabular}{|c|c|c|c|c|c|c|c|c|}
\hline \multirow[t]{2}{*}{ Maltreatment } & \multicolumn{4}{|c|}{ Prevalence of father's violence (\%) } & \multicolumn{4}{|c|}{ Prevalence of mother's violence (\%) } \\
\hline & Total $(n=1,093)$ & Boys $(n=546)$ & Girls $(n=547)$ & $\chi^{2}$ & Total $(n=1,093)$ & Boys $(n=546)$ & Girls $(n=547)$ & $\chi^{2}$ \\
\hline \multicolumn{9}{|l|}{ Lifetime } \\
\hline \multicolumn{9}{|l|}{ Physical assault } \\
\hline Overall & 37.1 & 39.3 & 34.9 & 2.25 & 35.7 & 35.6 & 35.8 & 0.01 \\
\hline Minor & 32.8 & 35.2 & 30.5 & 2.75 & 32.1 & 31.9 & 32.2 & 0.01 \\
\hline Severe & 21.2 & 21.3 & 21.1 & 0.01 & 20.2 & 19.6 & 20.8 & 0.25 \\
\hline Very severe & 6.4 & 7.4 & 5.3 & 1.98 & 5.6 & 5.1 & 6.0 & 0.42 \\
\hline Severe/Very severe ${ }^{a}$ & 21.6 & 21.7 & 21.5 & 0.01 & 20.6 & 20.0 & 21.2 & 0.24 \\
\hline Psychological aggression & 63.3 & 63.1 & 63.5 & 0.01 & 61.0 & 59.1 & 62.9 & 1.66 \\
\hline Nonviolent discipline & 74.0 & 74.8 & 73.2 & 0.36 & 76.2 & 74.9 & 77.5 & 1.06 \\
\hline Neglect & 29.1 & 27.6 & 30.6 & 1.22 & 27.2 & 27.0 & 27.4 & 0.03 \\
\hline \multicolumn{9}{|l|}{ Preceding year } \\
\hline \multicolumn{9}{|l|}{ Physical assault } \\
\hline Overall & 16.7 & 17.2 & 16.1 & 0.23 & 17.4 & 16.1 & 18.6 & 1.19 \\
\hline Minor & 13.3 & 13.1 & 13.4 & 0.01 & 14.5 & 13.4 & 15.5 & 1.02 \\
\hline Severe & 9.5 & 8.3 & 10.6 & 1.68 & 9.8 & 7.9 & 11.7 & $4.48^{*}$ \\
\hline Very severe & 2.9 & 2.4 & 3.3 & 0.78 & 2.6 & 1.5 & 3.7 & $5.23 *$ \\
\hline Severe/Very severe ${ }^{a}$ & 10.1 & 9.1 & 11.2 & 1.34 & 10.3 & 8.4 & 12.1 & $3.90^{*}$ \\
\hline Psychological aggression & 45.2 & 45.4 & 45.0 & 0.02 & 46.7 & 45.9 & 47.5 & 0.30 \\
\hline Nonviolent discipline & 58.6 & 58.5 & 58.7 & 0.00 & 63.3 & 61.5 & 65.1 & 1.54 \\
\hline Neglect & 21.2 & 20.6 & 21.8 & 0.27 & 21.2 & 20.2 & 22.3 & 0.73 \\
\hline
\end{tabular}

$a$ "Severe/ Very severe"=Experiencing either a severe level, a very severe level, or a combination of them $* p<.05$

generally stood at around .24 to .40 , indicating a low to moderate agreement between the self-reports of fathers and children. The agreement coefficients of reports were low, and even near to zero for severe physical assault, with only .13 for lifetime and .01 for preceding-year experiences.

\section{Agreement Between Mother and Child Reports}

The comparison of mother and child reports of maltreatment by mothers is shown in Table 4. Similar to the discrepancies found between father and child reports, the rates of childreported maltreatment were significantly different from those reported by mothers. Children reported higher occurrences of lifetime severe and very severe physical assault and neglect, as well as higher rates of severe and very severe physical assault in the preceding year. On the other hand, mothers were more likely to report both lifetime and preceding-year perpetration of minor physical assault, psychological aggression, and nonviolent disciplinary behaviors. The prevalence of overall physical assault in the preceding year was also greater in mother reports.

The analyses of agreement between matched mother and child reports revealed results similar to those obtained in the analyses of father-child matched data. The percentages of disagreement between reports ranged from $2.9 \%$ to $33.7 \%$. The kappa coefficients generally fell within the range of .24 to .38 , with the exceptional cases of very severe physical assault over lifetime (kappa $=.06)$ and in the preceding year $($ kappa $=.01)$. Overall, the agreement between mother and child reports of child maltreatment was low to moderate.

Factors Affecting the Disagreement Between Reports

The present study investigated the effect of certain factors on the disagreement between parent and child reports of minor physical assault (with higher rates in parent reports), and of severe or very severe physical assault (with higher rates in child reports). The factors may be child-related (e.g., child's age and education level) or parent-related (including parent's age, negative attribution, violence approval, social desirability, and face).

Father-Child Disagreement No significant relationship was found between the factors and the disagreement in lifetime prevalence of minor physical assault. Negative attribution and social desirability were found to be associated with the disagreement in father and child reports of minor physical assault in the preceding year. Negative attribution was 
Table 3 Comparison of father's and child's reports on father's maltreatment of child

\begin{tabular}{|c|c|c|c|c|c|c|c|c|c|c|}
\hline \multirow[t]{2}{*}{ Maltreatment } & \multicolumn{2}{|c|}{ Father's report } & \multicolumn{2}{|c|}{ Child's report } & \multirow[t]{2}{*}{$\chi^{2}$} & \multirow[t]{2}{*}{ Cohen's kappa } & \multicolumn{2}{|c|}{ Agreement $^{a}$} & \multicolumn{2}{|c|}{ Disagreement $^{b}$} \\
\hline & $n$ & $\%$ & $n$ & $\%$ & & & $n$ & $\%$ & $n$ & $\%$ \\
\hline \multicolumn{11}{|l|}{ Lifetime } \\
\hline \multicolumn{11}{|l|}{ Physical assault } \\
\hline Overall & 283 & 33.0 & 402 & 37.1 & 3.40 & .40 & 681 & 79.5 & 176 & 20.5 \\
\hline Minor & 279 & 32.6 & 356 & 32.8 & 0.01 & .39 & 697 & 81.3 & 160 & 18.7 \\
\hline Severe & 78 & 9.1 & 230 & 21.2 & $52.65 * * *$ & .26 & 779 & 90.8 & 79 & 9.2 \\
\hline Very severe & 17 & 2.0 & 69 & 6.4 & $21.71 * * *$ & .13 & 832 & 97.0 & 26 & 3.0 \\
\hline Severe/ Very severe ${ }^{c}$ & 78 & 9.1 & 234 & 21.6 & $55.33 * * *$ & .26 & 775 & 90.3 & 83 & 9.7 \\
\hline Psychological aggression & 563 & 65.7 & 687 & 63.3 & 1.18 & .33 & 554 & 64.6 & 303 & 35.4 \\
\hline Nonviolent discipline & 697 & 81.3 & 803 & 74.0 & $14.60 * * *$ & .29 & 579 & 67.6 & 278 & 32.7 \\
\hline Neglect & 154 & 17.9 & 316 & 29.1 & $32.63 * * *$ & .28 & 672 & 78.3 & 186 & 21.7 \\
\hline \multicolumn{11}{|l|}{ Preceding year } \\
\hline \multicolumn{11}{|l|}{ Physical assault } \\
\hline Overall & 163 & 19.0 & 181 & 16.7 & 1.80 & .29 & 622 & 72.6 & 235 & 27.4 \\
\hline Minor & 161 & 18.8 & 144 & 13.3 & $11.00 * * *$ & .31 & 626 & 73.1 & 231 & 27.0 \\
\hline Severe & 31 & 3.6 & 103 & 9.5 & $25.80 * * *$ & .25 & 694 & 80.9 & 164 & 19.1 \\
\hline Very severe & 5 & 0.6 & 31 & 2.9 & $13.63 * * *$ & .01 & 804 & 93.7 & 54 & 6.3 \\
\hline Severe/ Very severe ${ }^{c}$ & 32 & 3.7 & 110 & 10.1 & $29.05 * * *$ & .24 & 692 & 80.7 & 166 & 19.4 \\
\hline Psychological aggression & 462 & 53.9 & 490 & 45.2 & $14.66^{* * *}$ & .30 & 597 & 69.7 & 260 & 30.3 \\
\hline Nonviolent discipline & 613 & 71.5 & 636 & 58.6 & $34.78^{* * *}$ & .29 & 652 & 76.1 & 205 & 23.9 \\
\hline Neglect & 125 & 15.7 & 230 & 21.2 & $9.38 * *$ & .28 & 635 & 74.0 & 223 & 26.0 \\
\hline
\end{tabular}

$a$ "Agreement" $=\%$ (Father-yes; Child-yes) $+\%$ (Father-no; Child-no). ${ }^{b}$ "Disagreement" $=\%$ (Father-yes; Child-no) $+\%$ (Father-no; Child-yes). ${ }^{c}$ "Severe/ Very severe"=Experiencing either a severe level, a very severe level, or a combination of them

${ }^{*} p<.05$. ${ }^{* *} p<.01 . * * * p<.001$

positively related to the odds of such disagreement (adjusted $O R=2.08,95 \% C I=1.32,3.26, p<.01)$, whereas social desirability was negatively associated (adjusted $O R=0.43$, $95 \% C I=0.27,0.69, p<.001)$.

As for severe to very severe physical violence, no factor was significantly associated with the disagreement in the selfreported lifetime experience of violence, while social desirability was the only factor associated with the disagreement in severe to very severe physical assault (adjusted $O R=0.39$, $95 \% C I=0.21,0.71, p<.01)$. Specifically, a higher level of the father's social desirability leads to a decrease in the odds of disagreement between reports.

Mother-Child Disagreement For lifetime minor physical assault by mothers, the child's education level (adjusted $O R=$ $0.39,95 \% C I=0.19,0.81, p<.05$ ) and mother's age (adjusted $O R=0.41,95 \% C I=0.18,0.96, p<.05)$ were significantly associated with the mother-child disagreement. The child's age and the mother's level of violence approval were associated with the disagreement between reports of minor physical assault in the preceding year. An increase in the child's age decreased the odds of disagreement (adjusted $O R=0.82,95 \%$ $C I=0.71,0.94, p<.01)$, while an increase in the mother's violence approval increased the odds of disagreement (adjusted $O R=1.73,95 \% C I=1.06,2.83, p<.05$ ).

When focusing on the mother's lifetime perpetration of severe or very severe maltreatment, violence approval and face were significantly associated with the disagreement between mother and child reports. An increase in the odds of such disagreement was associated with an increase in the mother's violence approval (adjusted $O R=1.82,95 \% C I=1.11,2.97$, $p<.05$ ) and a decrease in the extent to which mothers valued saving face (adjusted $O R=0.69,95 \% C I=0.50,0.95, p<.05$ ). For the disagreement in severe or very severe physical assault in the preceding year, the mother's negative attribution was the only significant associated factor (adjusted $O R=0.70,95 \%$ $C I=0.49,0.99, p<.05)$. That is, the greater the mother's negative attribution, the lower were the odds of disagreement between mother and child reports.

\section{Discussion}

Using a large and representative parent-child matched sample, the present study investigated the prevalence of different types 
Table 4 Comparison of mother's and child's reports on mother's maltreatment of child

\begin{tabular}{|c|c|c|c|c|c|c|c|c|c|c|}
\hline \multirow[t]{2}{*}{ Maltreatment } & \multicolumn{2}{|c|}{ Mother's report } & \multicolumn{2}{|c|}{ Child's report } & \multirow[t]{2}{*}{$\chi^{2}$} & \multirow[t]{2}{*}{ Cohen's kappa } & \multicolumn{2}{|c|}{ Agreement $^{a}$} & \multicolumn{2}{|c|}{ Disagreement ${ }^{b}$} \\
\hline & $n$ & $\%$ & $n$ & $\%$ & & & $n$ & $\%$ & $n$ & $\%$ \\
\hline \multicolumn{11}{|l|}{ Lifetime } \\
\hline \multicolumn{11}{|l|}{ Physical assault } \\
\hline Overall & 374 & 39.9 & 390 & 35.7 & 3.72 & .37 & 738 & 78.8 & 199 & 21.2 \\
\hline Minor & 372 & 39.4 & 350 & 32.1 & $12.10 * * *$ & .38 & 749 & 79.5 & 193 & 20.5 \\
\hline Severe & 89 & 9.4 & 221 & 20.2 & $45.84 * * *$ & .24 & 858 & 91.0 & 85 & 9.0 \\
\hline Very severe & 16 & 1.7 & 61 & 5.6 & $20.86^{* * *}$ & .06 & 911 & 97.1 & 27 & 2.9 \\
\hline Severe/ Very severe ${ }^{c}$ & 90 & 9.6 & 225 & 20.6 & $46.79 * * *$ & .24 & 852 & 90.8 & 86 & 9.2 \\
\hline Psychological aggression & 657 & 69.8 & 666 & 61.0 & $17.34 * * *$ & .32 & 623 & 66.3 & 317 & 33.7 \\
\hline Nonviolent discipline & 783 & 83.1 & 832 & 76.2 & $14.85 * * *$ & .25 & 649 & 69.0 & 292 & 31.0 \\
\hline Neglect & 210 & 22.4 & 297 & 27.2 & $6.30^{*}$ & .30 & 733 & 78.1 & 199 & 21.2 \\
\hline \multicolumn{11}{|l|}{ Preceding year } \\
\hline \multicolumn{11}{|l|}{ Physical assault } \\
\hline Overall & 215 & 22.9 & 190 & 17.4 & $9.63 * *$ & .34 & 660 & 70.4 & 277 & 29.6 \\
\hline Minor & 214 & 22.7 & 158 & 14.5 & $22.91 * * *$ & .33 & 670 & 71.1 & 272 & 28.9 \\
\hline Severe & 36 & 3.8 & 107 & 9.8 & $27.77 * * *$ & .26 & 760 & 80.6 & 183 & 19.4 \\
\hline Very severe & 5 & 0.5 & 28 & 2.6 & $13.04 * * *$ & .01 & 876 & 93.4 & 62 & 6.6 \\
\hline Severe/ Very severe ${ }^{c}$ & 38 & 4.0 & 112 & 10.3 & $28.46^{* * *}$ & .28 & 756 & 80.6 & 182 & 19.4 \\
\hline Psychological aggression & 558 & 59.3 & 510 & 46.7 & $32.16^{* * *}$ & .34 & 645 & 68.6 & 295 & 31.4 \\
\hline Nonviolent discipline & 698 & 74.1 & 691 & 63.3 & $27.34 * * *$ & .29 & 707 & 75.1 & 234 & 24.9 \\
\hline Neglect & 178 & 19.0 & 232 & 21.2 & 1.64 & .31 & 698 & 74.4 & 240 & 25.6 \\
\hline
\end{tabular}

$a$ "Agreement" $=\%$ (Mother-yes; Child-yes) $+\%$ (Mother-no; Child-no). ${ }^{b}$ "Disagreement" $=\%$ (Mother-yes; Child-no) $+\%$ (Mother-no; Child-yes).

$c$ "Severe/ Very severe" =Experiencing either a severe level, a very severe level, or a combination of them

${ }^{*} p<.05 .{ }^{* *} p<.01 . * * * p<.001$

of father-to-child and mother-to-child maltreatment. Findings showed that over $60 \%$ of the child respondents had experienced at least one type of child maltreatment, reflecting that child maltreatment was not a rare phenomenon in Hong Kong. In line with past research findings (Chen and Dunne 2006; Pinheiro 2006; Shen 2006; Tang 2006; WHO 2002; Wong et al. 2009), the present study found that psychological aggression was the most common reported form of parent-to-child maltreatment, followed by minor physical violence, neglect, severe physical violence, and very severe physical abuse.

Overall, boys and girls were equally likely to report an experience of parental child maltreatment. Significant gender differences were found only for mother-to-child severe and very severe physical violence, for which girls reported higher occurrences of abuse. Contradicting previous findings that boys, subjected to stricter physical discipline due to higher parental expectations, were more prone to maltreatment (Tang 2006; Wong et al. 2009), the present results seem to support the argument that boys are less likely to be mistreated (Finkelhor 1994). The lower reported rates of child maltreatment among boys could be explained by their higher value as perceived by Chinese parents (Festini and de Martino 2004; Korbin 1991). On the other hand, the higher rates of parental abuse against girls might be due to their greater likelihood for being socialized to be more compliant and responsive to others' needs (Wellman 1993), as well as their higher tendency to disclose victimization experiences to others as they were more likely to receive positive reactions (Ullman and Filipas 2005)

\section{Parent-Child Disagreement in the Occurrence of Child Maltreatment}

The present study found significant disagreement between the experiences of parent-to-child maltreatment as reported by parents and children. The parent-child agreement, as measured by Cohen's kappa coefficients, was relatively low across different forms of child maltreatment. In particular, parents, regardless of their gender, were less likely to report severe and very severe physical violence against their children. On the other hand, they were more likely to report using minor physical assault, psychological aggression, nonviolent discipline, and neglect. The present finding may provide a piece of supporting evidence that parents tend to underreport severe forms of child abuse and regard their violent behaviors as less severe than children's reports. One possible explanation for this may be the fear of future consequences or court actions 
after admitting an offense of domestic violence (Appel and Holden 1998; Cicchetti and Olsen 1990; Edleson and Brygger 1986; Straus and Kaufman-Kantor 1994). Also, the discrepancy between parent and child understandings of discipline practices might influence the reporting of child maltreatment.

\section{Factors Affecting the Parent-Child Disagreement in Child Maltreatment}

To explore other possible explanations for the disagreement between children's and parents' reports, the present study investigated the associations of various child, parent, and family factors with the disagreement between reports. Several factors were found to be predictive of disagreement between self-reports of parents and children. Fathers' social desirability was the only significant predictor common to the disagreement between father and children reports in minor and severe plus very severe physical assault. In particular, a higher level of fathers' social desirability led to a lower disagreement between father-child matched reports. It is expected that a higher level of parents' social desirability would predict a greater tendency to underreport violence (Arias and Beach 1987; Rosenbaum and Langhinrichsen-Rohling 2006). From these findings, the lower level of disagreement between reports may imply that a child's underreporting of maltreatment is also affected by a higher level of fathers' social desirability, which may be attributed to a child's feelings of loyalty toward the abusive family or parent (Jaffe et al. 1992). If both father and child underreport child maltreatment, it will likely result in a lower level of disagreement between reports. However, how parents' social desirability affects the reporting of both parents and children may be worth investigating in future research.

In contrast, factors affecting mother-child disagreement on minor physical assault were more diverse, including the child's age, the mother's age being under 34 , and violence approval. As for mother-child disagreement on severe plus very severe physical abuse, factors included negative attribution, violence approval, and face. As the only common predictive factor for the discrepancy in self-reported minor and severe plus very severe physical assault, an increase in the mother's level of approval of the use of violence to discipline children was related to an increase in such discrepancies. That is, a mother who accepts violent acts as disciplinary practices may be more likely to regard severe physical abuse as minor corporal punishment. This may provide supporting evidence for the effect of violence approval on one's experience and reporting of violent behaviors (Jaffe et al. 1992).

\section{Limitations and Suggestions for Future Studies}

Some limitations must be noted in interpreting the present findings. Not only did the retrospective cross-sectional design restrict the study's ability to confirm causal relationship between reporting styles and associated factors, but it also might have affected the accuracy of respondent reports. Indeed, due to under- or overreporting, the actual prevalence of child maltreatment is almost impossible to determine. The present findings may support the argument that underreporting of severe physical assault perpetrated by parents is common. However, it is possible that the child reports may also be inaccurate due to recall bias. A longitudinal prospective design, which allows tracking of the occurrence of child maltreatment within the time frame, may be able to provide evidence to explain the causal relationship. However, several ethical issues must be addressed before one can adopt a longitudinal approach to the study of violence. One is whether or not to provide interventions in reported child abuse cases. Providing an intervention may confound the study results, but ignoring cases of abused children may be unethical. Future research might develop a better design by increasing the reliability of child maltreatment reporting while at the same time minimizing potential ethical problems.

Due to the limited resources available throughout the study period, child sexual abuse was not investigated, and children under the age of 12 were not interviewed in the present study. To offer a more complete profile of child maltreatment by parents, future studies might consider covering sexual abuse and examining the agreement between parent and child reports on such violence, as well as modifying the questionnaires and interview procedures so that younger children can participate.

\section{Practical Implications}

In conclusion, the present study provided evidence that child maltreatment is not uncommon among Chinese families in Hong Kong. The relatively high occurrence of different forms of child maltreatment reflects a need for greater public and research attention. Intervention is of great importance to existing child maltreatment cases, and accurate screening is the key to the provision of effective intervention. As shown by the present findings, the reliability of both parent and child reports is not as good as one may think. The significant discrepancies between parent and child reports may highlight the importance of simultaneously using reports from both parents and children in future screening and intervention programs for child maltreatment.

Acknowledgement This study was commissioned by Social Welfare Department, the Government of Hong Kong and funded by the Lotteries Fund.

Open Access This article is distributed under the terms of the Creative Commons Attribution Noncommercial License which permits any noncommercial use, distribution, and reproduction in any medium, provided the original author(s) and source are credited. 


\section{References}

Appel, A. E., \& Holden, G. W. (1998). The co-occurrence of spouse and physical child abuse: a review and appraisal. Journal of Family Psychology, 12(4), 578-599.

Arias, I., \& Beach, S. R. (1987). Validity of self-reports of marital violence. Journal of Family Violence, 2(2), 139-149.

Barnett, D., Manly, J. T., \& Cicchetti, D. (1993). Defining child maltreatment: The interface between policy and research. In D. Cicchetti, S. L. Toth, \& I. E. Sigel (Eds.), Advances in applied developmental psychology: Child abuse, child development, and social policy (pp. 7-73). Norwood: Ablex Publishing Corporation.

Bifulco, A., Brown, G. W., \& Harris, T. O. (1994). Childhood experience of care and abuse (CECA): a retrospective interview measure. Journal of Child Psychology and Psychiatry, 35, 1419-1435.

Briere, J. (1992). Methodological issues in the study of sexual abuse effects. Journal of Consulting and Clinical Psychology, 60, 196203.

Brown, J., Cohen, P., Johnson, J., \& Salzinger, S. (1998). A longitudinal analysis of risk factors for child maltreatment: findings from a 17 year prospective study of officially recorded and self reported child abuse and neglect. Child Abuse \& Neglect, 22(11), 1065-1078.

Chaffin, M., Kelleher, K., \& Hollenberg, J. (1996). Onset of physical abuse and neglect. Psychiatric, substance abuse, ans social risk factors from prospective community data. Child Abuse \& Neglect, 20(3), 191-203.

Chan, K. L. (2009a). Protection of face and avoidance of responsibility: Chinese men's account of violence against women. Journal of Social Work Practice, 23(1), 93-108.

Chan, K. L. (2009b). Sexual violence against women and children in Chinese societies. Trauma, Violence \& Abuse, 10, 69-85.

Chance, T., \& Scannapieco, M. (2002). Ecological correlates of child maltreatment: similarities and differences between child fatality and nonfatality cases. Child and Adolescent Social Work Journal, 19(2), 139-161.

Chen, J. Q., \& Dunne, M. P. (2006). Child maltreatment in China. In D. Daro (Ed.), World perspectives on child abuse (pp. 61-63). Chicago: ISPCAN.

Cicchetti, D., \& Manly, J. T. (2001). Operationalizing child maltreatment: developmental processes and outcomes. Development and Psychopathology, 13, 755-757.

Cicchetti, D., \& Olsen, K. (1990). The developmental psychopathology of child maltreatment. In M. Lewis \& S. M. Miller (Eds.), Handbook of developmental psychopathology (pp. 261-279). New York: Plenum.

Edleson, J. L., \& Brygger, M. P. (1986). Gender differences in reporting of battering incidences. Family Relations, 35(3), 377-382.

Fantuzzo, J. W., \& Lindquist, C. U. (1989). The effects of observing conjugal violence on children: a review of research methodology. Journal of Family Violence, 4, 77-94.

Festini, F., \& de Martino, M. (2004). Twenty five years of the one child family policy in China: problems and future prospects. Journal of Epidemiology and Community Health, 58(5), 358-359.

Finkelhor, D. (1994). Current information on the scope and nature of child sexual abuse. The Future of Children, 4(2), 31-53.

Graham-Bermann, S. A., DeVoe, E. R., Mattis, J. S., Lynch, S., \& Thomas, S. A. (2006). Ecological predictors of traumatic stress symptoms in Caucasian and ethnic minority children exposed to intimate partner violence. Violence Against Women, 12(7), 663692.

Hart, S. N., Binggell, N. J., \& Brassard, M. R. (1998). Evidence for the effects of psychological maltreatment. Journal of Emotional Abuse, $1,27-56$.

Ho, C. K. (1990). An analysis of domestic violence in Asian American communities: a multicultural approach to counseling. Women \&
Therapy. Special Issue: Diversity and Complexity in Feminist Therapy: I, 9(1-2), 129-150.

Hong, G. K., \& Hong, L. K. (1991). Comparative perspectives on child abuse and neglect: Chinese versus Hispanics and Whites. Child Welfare, 74, 189-204.

Hussey, J. M., Chang, J. J., \& Kotch, J. B. (2006). Child maltreatment in the United States: prevalence, risk factors, and adolescent health consequences. Pediatrics, 118, 933-942.

Jaffe, P. G., Sudermann, M., \& Reitzel, D. (1992). Child witnesses of marital violence. In R. T. Ammerman \& M. Hersen (Eds.), Assessment of family violence: A clinical and legal sourcebook (pp. 313331). New York, NY: John Wiley.

Jouriles, E. N., \& Norwood, W. D. (1995). Physical aggression toward boys and girls in families characterized by the battering of women. Journal of Family Psychology, 9, 69-78.

Jouriles, E. N., Mehta, P., McDonald, R., \& Francis, D. V. (1997). Psychometric properties of family members' reports of parental physical aggression toward clinic-referred children. Journal of Consulting and Clinical Psychology, 65, 309-318.

Kaufman, K. L., Hilliker, D. R., Lathrop, P., \& Daleiden, E. L. (1993). Assessing child sexual offenders' modus operandi: accuracy in selfreported use of threats and coercion. Sexual Abuse, 6, 213-229.

Kaufman, J., Jones, B., Stieglitz, E., Vitulano, L., \& Mannarino, A. P. (1994). The use of multiple informants to assess children's maltreatment experiences. Journal of Family Violence, 3, 227-247.

Kerig, P. K., \& Fedorowicz, A. E. (1999). Assessing maltreatment of children of battered women: methodological and ethical considerations. Child Maltreatment, 4, 103-115.

Kolko, D. J., Kazdin, A. E., \& Day, B. T. (1996). Children's perspective in the assessment of family violence: psychometric characteristics and comparison to parent reports. Child Maltreatment, 1, 156-167.

Korbin, J. E. (1991). Cross-cultural perspectives and research directions for the 21st century. Child Abuse \& Neglect, 15(Suppl 1), 67-77.

Lampe, A. (2002). Prevalence of sexual and physical abuse and emotional neglect in Europe. Zeitschrift für Psychosomatische Medizin, 48, 370-380.

Landis, J. R., \& Koch, G. G. (1977). The measurement of observer agreement for categorical data. Biometrics, 33, 159-174.

Maxwell, B. (1996). Translation and cultural adaptation of the survey instruments. In M. O. Martin \& D. L. Kelly (Eds.), Third International Mathematics and Science Study (TIMSS) Technical report, Volume 1: Design and development (pp. 159-169). Chestnut Hill: Boston College.

May-Chahal, C., \& Cawson, P. (2005). Measuring child maltreatment in the United Kingdom: a study of the prevalence of child abuse and neglect. Child Abuse \& Neglect, 29, 969-984.

McGee, R. A., \& Wolfe, D. A. (1991). Between a rock and a hard place: where do we go from here in defining psychological maltreatment? Development and Psychopathology, 3, 119-124.

McGee, R. A., Wolfe, D. A., Yuen, S., Wilson, S. K., \& Carnochan, J. (1995). The measurement of child maltreatment: a comparison of approaches. Child Abuse \& Neglect, 19, 233-249.

McGee, R. A., Wolfe, D. A., \& Wilson, S. K. (1997). Multiple maltreatment experiences and adolescent behavior problems: adolescents' perspectives. Development and Psychopathology, 9, 131-150.

Pinheiro, P. S. (2006). World report on violence against children. New York: United Nations Secretary General's Study on Violence against Children.

Richters, J. E., \& Martinez, P. (1993). The NIHM Community Violence Project I: children as victims and witnesses to violence. Psychiatry: Interpersonal and Biological Processes, 56, 7-21.

Rosenbaum, A., \& Langhinrichsen-Rohling, J. (2006). Meta-research on violence and victims: the impact of data collection methods on findings and participants. Violence and Victims, 21(4), 404-409. 
Runyan, D., Cox, C. E., Dubowitz, H., Newton, R. R., Upadhyaya, M., Leeb, R., \& Kotch, J. B. (2005). Describing maltreatment: do child protective service reports and research definitions agree? Child Abuse \& Neglect, 29, 461-477.

Scher, C. D., Forde, D. R., McQuaid, J. R., \& Stein, M. B. (2004). Prevalence and demographic correlates of childhood maltreatment in an adult community sample. Child Abuse \& Neglect, 28(2), 167-180.

Shen, A. C. (2006). The co-occurrence rate of marital violence and child maltreatment: a case study of Nantou County. Chinese Journal of Mental Health, 19(4), 330-363.

Shor, R. (1998). Pediatricians in Israel: factors which affect the diagnosis and reporting of maltreated children. Child Abuse \& Neglect, 22(2), 143-153.

Straus, M. A. (2007). Conflict tactics scales. In N. A. Jackson (Ed.), Domestic violence (pp. 190-197). New York: Routledge: Taylor \& Francis Group.

Straus, M. A., \& Kaufman-Kantor, G. (1994, July). Change in spouse assault rates from 1975 to 1992: A comparison of three national surveys in the United States. Paper presented at the World Congress of Sociology, Bielefeld, Germany.

Straus, M. A., Hamby, S. L., Finkelhor, D., Moore, D. W., \& Runyan, D. (1998). Identification of child maltreatment with the ParentChild Conflict Tactics Scales: development and psychometric data for a national sample of American parents. Child Abuse \& Neglect, 22(4), 249-270.

Straus, M. A., Hamby, S. L., Boney-McCoy, S., \& Sugarman, D. (1999). The personal and relationships profile. Durham: Family Research Laboratory, University of New Hampshire.
Tang, C. S. K. (2006). Corporal punishment and physical maltreatment against children: a community sample on Chinese parents in Hong Kong. Child Abuse \& Neglect, 30(8), 893-907.

U. S. Department of Health and Human Services. (2003). The Child Abuse Prevention and Treatment Act. Retrieved from: http://www.acf.hhs. gov/programs/cb/laws_policies/cblaws/capta03/capta_manual.pdf.

Ullman, S. E., \& Filipas, H. H. (2005). Gender differences in social reactions to abuse disclosures post-abuse coping, and PTSD of child sexual abuse survivors. Child Abuse \& Neglect, 29(7), $7676-782$.

Wang, H. (2002). Help seeking tendency in situation of threat to self-esteem and face-losing. Hong Kong: The University of Hong Kong.

Wellman, M. M. (1993). Child sexual abuse and gender differences: attitudes and prevalence. Child Abuse \& Neglect, 17(4), 539-547.

Winegar, R. K., \& Lipschitz, D. S. (1999). Agreement between hospitalized adolescents' self-reports of maltreatment and witnessed home violence and clinician reports and medical reports. Comprehensive Psychiatry, 40(5), 347-352.

Wong, W. C. W., Leung, P. W. S., Tang, C. S. K., Chen, W. Q., Lee, A., \& Ling, D. C. (2009). To unfold a hidden epidemic: prevalence of child maltreatment and its health implications among high school students in Guangzhou, China. Child Abuse \& Neglect, 33(7), 441-450.

World Health Organization. (2002). World report on violence and health. Geneva: Author.

World Health Organization. (2004). International classification of diseases (ICD). Geneva, Switzerland: Author. 